\title{
Changing Suburban Daily Mobilities in Response to a Mobility Intervention: A Qualitative Investigation of an E-bike Trial
}

\author{
Ragnhild Dahl Wikstrøm *(D) and Lars Böcker ${ }^{(D)}$ \\ Department of Sociology and Human Geography, University of Oslo, 0317 Oslo, Norway; \\ lars.bocker@sosgeo.uio.no \\ * Correspondence: r.d.wikstrom@sosgeo.uio.no; Tel.: +47-93467130
}

Received: 17 February 2020; Accepted: 15 March 2020; Published: 19 March 2020

check for updates

\begin{abstract}
This paper explores how local mobility interventions can bring about changes in daily mobilities and presents a qualitative study of an intervention introducing electric bikes (e-bikes) to suburban commuters in Norway. Our research shows promising evidence that e-bikes could play a crucial role in achieving a sustainable transport transition and that interventions are essential to stimulate the upscaling and mainstreaming of this emerging low-energy transport mode. In order to understand the scheme's capacity to change mobility outcomes, this paper considers (i) how this low-energy mobility intervention was conceived and undertaken by its initiators, as well as how it was experienced by its participants; and (ii) how new e-bike practices are intertwined with existing daily activities and mobility systems. Theoretically, this paper draws on the staging mobilities framework and conceptualizes situational mobilities as involving the dimensions of embodiment, social interaction, and materiality. With this twofold objective, this paper generates crucial knowledge that is required to understand the capacity of mobility interventions to trigger a sustainable transport transition. This study explores the potential of combining mobile methods (GPS-tracking), qualitative GIS, and visual methods (photo- and map-elicitation) in interviews, and participant observations.
\end{abstract}

Keywords: sustainable mobility interventions; e-bike; suburbs; daily mobilities; qualitative GIS; mobility transition; materiality; embodied performance; social interaction

\section{Introduction}

Mobility challenges are not confined to urban cores, as suburbs are often associated with car usage and are seen as a hindrance to sustainable development. Unlike the monofunctional suburbs of the past, many of today's post-suburban landscapes have a high density of workplaces [1]. This mixing of land uses comes with new mobility challenges. The relative ease of driving in the opposite direction to peak traffic flows, the abundance of parking at suburban work locations, and difficulties with public transport egress make commuting to suburban work locations by car highly attractive. Several studies on density and travel behavior in different geographical contexts have found that "workers at suburban workplaces tend to commute more often by car and less often by public transport than their counterparts at inner-city workplaces do" [2] (p. 2042).

New travel modes, such as electric bikes (e-bikes), can play a crucial role in the transition towards a low-carbon society in suburban areas. By alleviating time, space, and bodily constraints and offering extended range [3-7], e-biking could become a more attractive and competitive transport mode than ordinary cycling. Despite its increased popularity, e-biking is still a niche phenomenon. Research on the early adopters of e-bikes [3-5,7-9] has detected barriers to adopting e-biking, such as bicycle weight, range anxiety, price, interaction with other road users, limited cycling infrastructure, weather, safety, 
security, and social stigma. Interventions are essential to stimulate the upscaling and mainstreaming of this emerging low-energy transport mode, and studies have found that participating in e-bike trials could trigger interest in future e-biking and cycling [6].

This paper addresses four important knowledge needs in the literature on sustainable mobility interventions. First, while being focused on inner-city cases, knowledge on interventions in suburban locations is currently lacking. Second, there is a need for a deeper understanding of the ways in which interventions trigger a systemic change in daily mobilities, including the co-evolution of technological innovations, institutions, norms and culture, and practices [10]. Much of the literature on systemic transitions is rooted in approaches using a multilevel perspective [11,12] or strategic niche management [13]. These perspectives are useful as a theoretical backdrop for understanding the interplay between the technological and institutional conditions under which innovations such as e-bikes are brought to the market; however, they largely fail to take into account how interventions into such conditions trigger changes in everyday mobility practices and affect user demand $[10,14,15]$. Third, to understand how mobility practices are (re)produced, it is necessary to consider how low-energy mobility interventions and innovations are performed and experienced and how new mobility practices interlock with daily activities and connect with existing mobility systems [16-19]. Fourth, this requires a perspective on mobility that goes beyond the hegemonic econometric conceptualization of movement as a derived demand, i.e., a perspective that captures the situationality, embodied performativity, and relationality of mobility interwoven with other daily practices $[18,20]$.

To address these knowledge needs, this paper discusses how mobility interventions can trigger systemic changes in suburban daily mobilities by examining an empirical case study of an e-bike intervention introducing e-bikes to suburban commuters in Bærum, Norway.

We have formulated the following two objectives:

(1) To assess how a low-energy mobility intervention is conceived by the initiators of e-bike schemes, and how it is performed and experienced by its participants;

(2) To explore how new e-bike practices may be interwoven with existing daily activities and mobility systems.

To address these objectives, this paper theoretically draws on the staging mobilities framework and conceptualizes situational mobilities as embodied performance in the interplay with the materialities of travel environments and social interactions, staged from above by structures and policy interventions and from below by individuals [21]. Methodologically, this paper captures the microgeographies and situational practices and experiences of an e-bike intervention through a novel combination of mobile methods (GPS-tracking), qualitative GIS, visual methods (photo- and map-elicitation) in interviews, and participant observations. The next section introduces the case study and methods. Then, this paper presents the framework of the staging mobilities, which is combined with other theoretical conceptualizations that are useful for gaining a better understanding of situational mobilities and how they connect to the mobility system. This study goes on to further discuss these theories along with empirical material in the analysis. This paper ends with a conclusion and discussion, including policy and design implications that may contribute to the implementation of a more sustainable mobility system.

\section{Introducing the Case and Methods}

This study took place in Bærum (population 126,841 in 2019), a suburban municipality bordering the Norwegian capital, Oslo. The rationale for selecting this site to study the capacity of an e-bike trial to change suburban mobility practices is fivefold. First, this study area benefits from a national, regional, and local policy landscape that is supportive of climate mitigation strategies. With nearly $100 \%$ renewable electricity production in Norway, emission reduction strategies in Norwegian municipalities, including in Bærum, are more focused on the transport sector than those in other countries. Some of these efforts target a modal shift away from car usage, such as zero-growth agreements for car traffic, 
suburban transit-oriented densification strategies [22], and reinvestments of road toll earnings into public transport and bicycle infrastructure [23]. Second, emission reduction strategies in transport often target the upscaling of electric mobility. The best-known examples of this are the strong incentives for electric cars, which, combined with other favorable conditions like low electricity prices, have led to world-leading and continuously-increasing electric vehicle (EV) EV shares in Norway generally (7\%), and in this study region in particular (Oslo 12\%; Bærum even 16\%) [24]. Electric bicycles are also growing in popularity. Unlike EVs, there are no large-scale national policies on electric bicycles, yet local initiatives, such as the municipal e-bike trial in this study, are increasingly being implemented, and policymakers are eager to learn about their effectiveness. Third, as it is among Norway's wealthiest and most educated municipalities, Bærum is well-positioned to implement innovations and new mobility solutions. Moreover, coordinated strategies on the upscaling of innovations rank highly on local policy agendas-for instance, via the Smart-city Bærum public-private partnership, which was the initiator of the e-bike trial presented in this study. Fourth, despite its potential to implement new mobility solutions, Bærum currently faces striking mobility challenges in terms of its dependence upon automobiles and road congestion that require urgent policy attention. Despite being central to Oslo and benefiting from its extensive urban-regional rail, metro, tram, and bus networks, Bærum has Norway's highest car ownership rates (93.6\% of households own a car; $45.9 \%$ own two or more) and relatively high car usage (61.4\% of trips by car) [25]. Fifth, Bærum stretches over a mixed-density suburban landscape with medium-level distances between origins and destinations, yielding a strong but largely untapped potential for e-biking. While currently being predominantly traversed by car, these medium-range distances $(2-10 \mathrm{~km})$ are where e-bikes have a competitive edge in terms of speed versus flexibility, both compared to slower walking and cycling modes, and to the car and public transport modes that perform better over longer distances. Substantial variations in altitude in the region, typically a barrier for ordinary cycling, might be an additional factor that is beneficial to e-bike usage.

This study employs different creative methods that help to capture the complexity of participants' engagement in the interventions and experienced spaces of daily mobilities. Studying the mobile performance and experience of participating in a trial scheme provides a unique opportunity to explore the construction of meaning in the practice of e-biking. Commuting practices are central in this study because this intervention aims to increase the bike share in commuting; a prerequisite for participating in the scheme is that one's workplace is located in the municipality. However, mobility practices other than commuting are also included, as participants were free to use their e-bikes for any type of trip. Moreover, commuting is not an isolated travel practice, as it is entangled with other daily practices, such as grocery shopping, taking children to school, etc.

All participants in this study were interviewed after the trial period, and GPS tracking, qualitative GIS, and visual methods (photo- and map-elicitation) were used to support the interviews. GPS-tracking is a mobile method [26] that is particularly useful for capturing the microgeographies of movement [27]. All participants were GPS-tracked on their e-bike trips during the trial periods of 7-14 days. The participants' GPS-tracks were visualized using Geographic Information Systems (GIS), and maps were printed out and discussed in semi structured interviews. This is a form of map-elicitation, whereby the participants generate the data used to make the maps. The visual and elicitative powers of GIS, and combining the GIS output with visual elicitation techniques (map-elicitation), were conducive to developing detailed discussions on mobile and socio-spatial experiences in the interviews [28]. The analysis of the GPS-data using GIS also generated interview questions that were tailored to each participant, such as "why have you taken two different routes between home and work?".

The participants also took pictures during the trial period that were submitted in advance and geotagged during the interviews. Photography is no longer a privilege of professionals and the elite, at least not in the Norwegian context, where the norm is to own a camera phone. Taking photos has become an integrated part of daily life [29,30], something that enables researchers to more efficiently incorporate visual methods into research designs. Photos can provide highly detailed information 
about in situ experiences in daily life. Moreover, giving participants the task of taking pictures can make them more conscious about their daily lives and spatial surroundings, and reflect upon details that might have otherwise been overlooked [31]. It was emphasized that the participants could take pictures of whatever they wanted. Still, two prompts were used as examples of what they could take photos of: 1) barriers/negative experiences and 2) enablers/positive experiences. Both the map- and photo-elicitation helped to facilitate discussion and evoke the informant's place-specific memories and mobile experiences. Combining visual and mobile methods in this way contributed to insights into daily mobile experiences, which are difficult to capture in traditional interviews [32].

Participant observation among those working for the e-bike scheme was also carried out. The participant observations involved travelling with and talking to these workers and delivering the e-bikes to the informants. Participating in their work contributed to essential knowledge and insight into how the scheme was carried out. The municipality of Bærum recruited 21 informants for this study in the same way as they recruit people and companies to join the scheme, and all those participating in the scheme at the time of data collection participated in this study. The data collection was set for the spring, which is the period when the bike season starts for many people. This was also to avoid the winter, as many people prefer not to bike when it is snowy, icy, and cold. The informants worked in both private businesses and public services. All the travels captured by GPS-trackers and a selection of pictures taken by the participants representing various types of performance and experiences are depicted in Figure 1 (pictures: a-z).

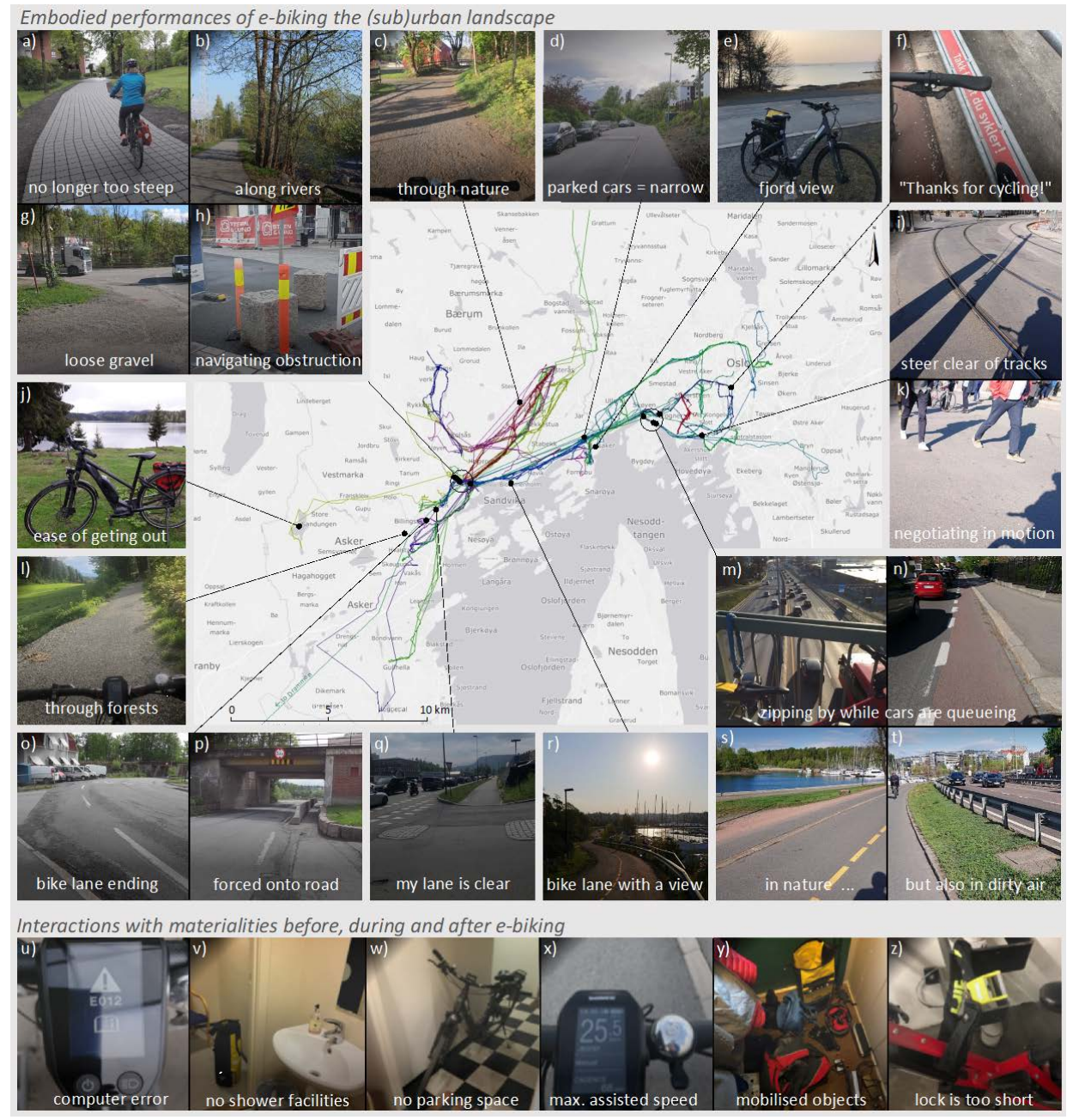

Figure 1. Embodied performance of e-biking the (sub) urban landscape and interactions with materialities before, during, and after e-biking. Pictures $(\mathbf{a}-\mathbf{z})$ were taken by the participants. 


\section{Framing Sustainable Mobility Interventions}

Strengers and Maller [33] argue that there are three dominant understandings of interventions and methods of intervening. The first type of intervention aims to change an individual's decisions and behaviors. The second type of intervention focuses on intervening in decision-making through market mechanisms, such as demand management schemes. The third type of intervention involves introducing new technologies, which suggests that technological innovations can fix societal challenges, such as climate change. Arguably, a fourth dominant intervention should be added to these three: changing the physical landscape through planning and design [34]. Importantly, not only do policy interventions and local experiments have the potential to trigger changes in sustainable mobility, they can also yield strategic marketing value [10]. For instance, e-bike schemes or self-driving busses can be useful tools for marketing cities as smart or environmentally friendly.

The dominant types of interventions or mechanisms in which transport is thought to be decarbonized have been criticized for not being able to bring about the change needed $[34,35]$. One of the responses has been an increase in practice-based research on innovations and interventions [15]. Spurling and McMeekin [19] argue that there are three ways climate change policies can facilitate social change by intervening in social practices. The first framing involves recrafting resource-intensive practices. Policymakers can aim at influencing a combination of elements of existing practices so that the practices can become more sustainable. An example is to promote more energy-efficient vehicles, including electric vehicles. This intervention does not fundamentally challenge the current practices of owning and travelling by private cars, only the resource intensity of such practices. The second framing involves substituting practices, suggesting that policies can aim at replacing less sustainable practices with more sustainable alternatives, such as by promoting a modal shift, from cars to e-bikes. The third and last framing is more complex and deals with changing how practices interlock, suggesting policies to shift focus to the bundles of practices that might comprise a more sustainable society. Subsequently, policymakers should then seek to intervene in the complex interconnections between different practices and must, therefore, consider the spatiotemporal rhythms with which daily practices are entangled.

This paper argues that even though sustainable transport interventions usually do not explicitly seek to intervene in the structure of everyday life, they may indirectly do so as different practices are always entangled. For example, the practice of commuting is inseparably connected to the broader spatiotemporal rhythms of daily life made up of practices like taking children to school, sleeping, having breakfast, working, and shopping for groceries. Time geography approaches $[16,36]$ capture this complexity with the concept of time-space constraints, resulting from the timing and location of all such voluntary or compulsory activities respective to one another and one's home location. Centrally located home locations and access to fast and flexible transport resources can partially lift such time-space constraints. Thus, to understand an intervention's capacity to trigger change, it is necessary to research how the intended new mobility practices interweave with people's other daily practices and which parts of everyday life are perceived as possible to structure in new ways. Mobility practices are always embedded in a larger mobility system, and it is, therefore, important to understand how a new mobility practice (dis)connects with the existing mobility system $[10,18]$.

\section{Staging Daily Mobilities}

The staging mobilities framework was developed by the mobilities scholar, Ole B. Jensen [21]. The framework is analytically centered on the performance of mobility practices. These mobility practices are dynamically staged from above by planning, design, regulations, and institutions. Staging from above is not necessarily restricted to formal top-down institutions, but also includes the ways mobilities are shaped, such as by local, grassroots, and bottom-up initiatives. The studied e-bike scheme is a low-barrier experiment, where commuters can try-out and familiarize themselves with e-biking over a short period, usually two weeks. This intervention thus stages the new mobility practice from above by lending out e-bikes and related equipment, such as helmets, panniers, and locks, for free. 
The conceived objective of this intervention is to kick-start a low-energy mobility practice of e-biking to work in the hope that it will provide a substitute [19] for the carbon-intensive practices of commuting by car and benefit society in terms of public health and emission reductions [37]. By ultimately targeting the eventual purchase of e-bikes, the scheme does not intend to promote a shift away from individual ownership, such as more radical innovations like bike-sharing schemes.

In addition to being staged from above, participants also stage their mobilities from below through their engagement with the intervention and the new mobility practice [21]. Travelling with low-energy mobility solutions to represent one's convictions or identity is an example of staging mobility practices from below. This does not mean that conscious and reflexive choices inform all mobile situations, but they can be part of the staging. The intervention is performed and experienced on the ground by those participating in the scheme, and taking part in the trial allows the participants to obtain situational experiences and stage their mobility from below in new ways, which might trigger a change in their future mobility practices.

The staging mobilities framework includes both the material and immaterial aspects involved in mediating mobility practices and encompasses the physical, social, technical, political, and cultural conditions of contemporary mobilities. Jensen [21] divides mobile situations into three analytical domains: physical settings and material spaces, embodied performance, and social interactions (Figure 2). The experiences of the participants in the e-bike scheme will now be discussed in reference to these three analytical domains.

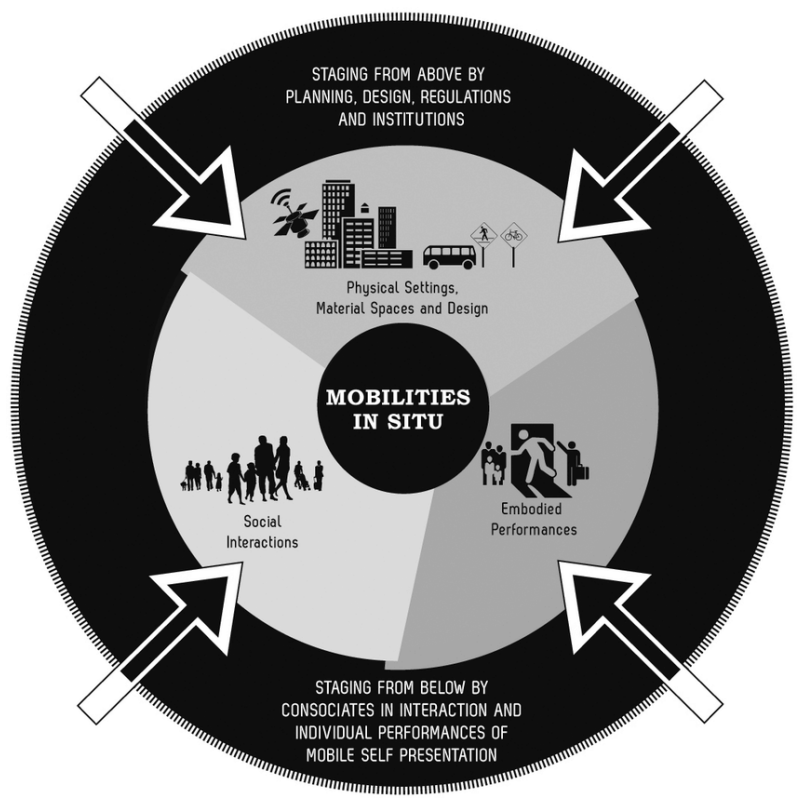

Figure 2. The staging mobilities model [21] (p. 6). Reproduced with permission from Ole B. Jensen, Staging mobilities; published by Routledge, 2013.

\subsection{Physical Settings, Material Spaces, and Design}

When moving, one interacts with different forms of materiality. Built environments and infrastructures are vital in both enabling and preventing particular mobilities [21]. An extensive body of literature within transport studies has focused on the relationship between the built environment and travel behavior. Studies, both internationally [38-40] and in the Nordic countries [2,41-43], typically highlight that people travel shorter distances and less often by private car in areas with high density, mixed land or building usages, compact street designs, and in proximity to city centers. However, there is a need to move beyond this instrumental understanding of materiality in transport studies and focus on how people interact with materialities at different stages of their travels, before, during, and after e-biking. 
Jensen [21] captures the material context for mobility by highlighting the role of the built environment in which mobilities are performed: configurations of buildings, transport infrastructures, public spaces, and street furniture in differing degrees of density, diversity, and design. Drawing on the work on dynamic situational travel environments by Martin Dijst [44], this paper argues that the material conditions for the performance and experience of mobility extend beyond this rather static and merely anthropogenic notion of the built environment. Firstly, natural elements, such as elevation, reliefs, soil types, water bodies, flora, fauna, air, and weather, are important. Secondly, both anthropogenic and natural material elements are always comprised of dynamic processes rather than static conditions. These processes can be fast and visible (e.g., traffic flows, air pollution, and weather) or slow and incremental (e.g., changes in land uses and infrastructure or erosion). Thirdly, materials are not just present in the built environment, but some are also actively brought along by travelers to customize or enhance their mobility performance and experiences. Examples in the context of e-biking include the e-bikes themselves, detachable batteries, locks, breaks, lights, and elements like clothing, helmets, panniers, reflective vests, headphones, (sun)glasses, mobile phones, bags, the items we carry to the office, or the groceries we carry back home. Several participants in this study expressed frustration with the pannier they borrowed from the scheme. Elisabeth, one of the informants, said that the pannier caused so much frustration that it ruined the whole experience. Accordingly, design elements and mobile objects can play a crucial role in the success of the intervention.

Material infrastructure is often conceptualized as immobile and fixed structures or "moorings" that enable mobilities, such as bike sheds, car parks, or docks [45]. However, infrastructures can also be seen as enabling stillness [46]. For example, bicycle parking spaces can play an active role in staging daily e-biking by allowing one to stop and leave their e-bike at the destination where one is conducting an activity. The findings show that parking the e-bike enables daily activities but also creates challenges, and parking issues for different modes affect the relative competitive advantage of the e-bike. Both conventional bikes and e-bikes can often be parked flexibly in front of a destination. An area does not need to be a designated a "parking space" for it to become a space to park a bike, as it can be easier to "create" or negotiate parking spaces for bikes [47]. Several participants stressed that this direct access reduces the hassles of "the last mile" associated with the car and public transport use, i.e., walking to and from the car park or public transport stop. Astrid, one of the participants who tried an e-bike for the first time, pointed out that with the e-bike she could park right outside her workplace. In contrast, when she commuted by car, she needed to walk for about 15 minutes from the car park. That meant she would have to be outside in the weather to walk this "last mile", which made her conclude that she "might as well bike to work, regardless of the weather." This quote highlights the accessibility and flexibility advantages of the e-bike relative to the car (and arguably also public transport), as well as how the lack of access to car parking (or a public transport stop) nearby the workplace makes it less attractive to use such modes, regardless of the weather.

Nevertheless, many of the interviewees were hesitant to park their e-bikes at non-designated parking spaces, especially in urban areas, because of safety reasons, and the challenges of parking the e-bike were frequently brought up in the interviews. Several participants stressed that the e-bike was expensive; therefore, they saw a need for secure and safe parking spaces. In general, parked bikes can be vulnerable to theft, vandalism, and weather conditions, and the high price of the e-bike can reinforce the fear of something happening to it $[47,48]$. The fear of the e-bike, or parts of the e-bike, being stolen was, for many participants, reinforced by the fact that they borrowed the e-bike. As Emma explains: "Especially since it is not my bike, I don't dare to leave it standing out by the road." Moreover, e-bikes have detachable elements that can be removed and stolen. The employees working for the scheme stressed this when delivering the e-bikes to the participants and explained the importance of removing and bringing the computer with them when they parked the e-bike, as it was a "popular" item to steal. The computer is small and easy to detach from the bike and small enough to put in a pocket. However, it is "one more thing to remember" and can make it more cumbersome to park an e-bike compared to a conventional bike. Some of the participants interviewed worried that other detachable 
elements could also be stolen, such as the battery (even though the battery was locked onto the bike) and therefore brought it with them when parking. The battery is larger and more impractical to bring along. Lisa perceived it as inconvenient to use the e-bike for running several errands on the same trip because of this: "There were moments where I could have stopped, or where I might have needed to go to the store, but where I thought-no, I couldn't bother-because there is so much hassle, to lock it and then bring all the things in. However, it might be that if I had an e-bike and had been more accustomed to cycling, then I might not have cared so much about it, then I would have figured it out. But I didn't because it seemed very cumbersome." Her quote shows that experience is needed to determine how to solve the daily issues of parking the e-bike when running errands. The intervention allowed the participants to gain some experience, although two weeks might not have been enough time. Emma highlighted the lack of safe and secure parking spaces at home (see Figure 1w). This awareness triggered her to suggest to the condominium to build a communal lockable bike shed. Accordingly, participating in an intervention can create awareness and result in actions that reinforce the potential of the intervention to trigger change.

Many informants also stressed that the bike lock they borrowed from the scheme was too short (see Figure 1z, taken by Edvard). The short bike lock was not compatible with the design of many bike racks, which made it difficult to park and lock the e-bike at certain places. Accordingly, the difficulties with locking and parking made some participants avoid using the e-bike for certain trips and activities. This exemplifies how bike locks can have different scripts, affordances, and meanings [48]. Moreover, these situational experiences of parking e-bikes show how immobile infrastructures and mobile objects, such as a bike lock, can play an active part in staging the practice of e-biking from above [21,46-48].

There are also other amenities or immobile infrastructures that affect the experience of e-biking. Informants highlighted the importance of having facilities like changing rooms and showers at their workplace. Even when using an e-bike, many found the need to change clothes, and possibly shower, when arriving at work. Karoline, a participant who had one of the longest commutes, highlighted the lack of such amenities: "We don't have the opportunity to shower here before work, and I, therefore, took this picture (Figure 1v) to show our horrific changing room." Other participants expressed the lack of spacious and comfortable changing rooms. There were also examples of informants satisfied with the amenities at work who highlighted how necessary these facilities were for them to be able to use an active travel mode to commute to work. Accordingly, what happens before A (the "starting" point of travel) and after B (the "ending" point of travel) is crucial for the experience of traveling and plays a mediating role in enabling or preventing one from choosing specific transport modes. Arguably, mobile objects and the amenities at the departure and arrival locations are essential elements of the (im)mobile material infrastructure facilitating mobility practices.

\subsection{Embodied Performance}

Jensen notes that, "The mobile body is the entry point to understanding the individual's engagement with the world and is the key to seeing the way meaning and norms are created in embodied cultures of mobilities" [21] (p. 119). Accordingly, embodiment is an essential part of how mobilities unfold, which is especially important for a physically-active and open-air transport mode like e-biking.

\subsubsection{Lifting Capability Constraints}

The body interacts with materialities in different and new ways when e-biking. The electric motor, battery, and computer change the cycling experience. It takes less effort to cycle, especially in demanding topographical landscapes, as well as in urban or suburban landscapes where cycling momentum is regularly interrupted by stops and traffic. An e-bike may also increase the distance people are willing to cycle or the distance they are able to travel in a limited amount of time $[4,6]$. As depicted in the map, some informants even rode their e-bike through the woodlands for longer leisure trips during the weekend. However, the findings indicate that the e-bike was perceived as best 
suited for medium-range distances. The ability to bike up a steep hill with an e-bike is depicted in picture a (Figure 1a), taken by Marie, who expressed this experience as empowering, as she was able to do something that she was not able to do before. The battery replaces some of the human muscle-power needed to cycle, and parts of the act of moving are delegated to the e-bike [49]. Furthermore, the delegation of the work of movement also prescribes back on the biker and the mobile embodied performance, as it can help reduce fatigue when cycling. Mia, a participant who had been in an accident several years ago, was able to use the e-bike because some of the muscle power needed to cycle was delegated to the materiality of the e-bike, which enabled her to use an active travel mode again. Electric power also helped reduce the burden of weight for many and made it easier to carry small goods, such as a small number of groceries. As such, the processes of delegation and prescription shed light on how the mobile body and material are coupled, how materiality affects embodied cycling experiences, and how material elements form enablers and barriers for combining e-biking with other daily practices and for adopting e-biking in the future.

By reducing the physical effort required to cycle, the e-bike can also reduce undesirable bodily reactions such as sweat and thus reduce the need to shower. As expressed by Edvard, "It's easier; you don't sweat, for example, and you can bring more stuff with you without noticing a big difference; you won't get sweaty or cold if you take a detour, so it is sort of lowering the threshold. Also, I can cycle longer distances, such as a trip to the other side of the city to visit my parents, something I would not have been able to do on a conventional bike because then I would have been too exhausted and sweaty, but with an e-bike it's fine." The reduction of sweat was seen by many as a great advantage of the e-bike and made it more viable to travel by bicycle for visiting friends and family or going directly to meetings after a commute. On the other hand, Edvard and other informants were also afraid of riding the e-bike for longer trips because of its battery capacity. The e-bike thus created a form of range anxiety, often associated with electric cars, but also a perception affiliated with e-biking [7]. Even though it is possible to use the e-bike without any battery power left, many informants commented that the weight of the e-bike made it exhausting to cycle without the help of the battery.

Cycling on an e-bike changes one's relative strength and speed, which changes the dynamics of cycling together. As Marie explains, "My husband cycled on a normal bike, and I cycled on the e-bike, I felt that I only cycled downhill, and he felt he cycled more uphill. I felt that I biked slowly, but he felt that I biked faster than I usually do. Therefore, we agreed that we would not bike together in this period. Thus, instead, we biked separately." Accordingly, she perceives the e-bike to be best suited for trips done by herself or together with other e-bikers. Iris, who is also used to cycling frequently, had the opposite experience: "With the e-bike, I can finally keep up with my husband. We don't usually bike together, but when I had the e-bike, we could". However, the most prominent finding related to riding together with friends and family was that it was a disadvantage to be the only one with an e-bike because of the speed difference and change in relative strength. Moreover, not being able to ride together with one's partner on an e-bike was perceived by several informants as a barrier to purchasing one. Some highlighted a desire for buying two or more e-bikes to solve this problem, but that raised a new barrier: higher expenses.

The e-bike also altered the way people associate cycling with exercise and health. Because of the electric motor assistance, there were mixed perceptions about whether or not one was working out when e-biking. Some informants expressed that e-biking was great for getting exercise, while others emphasized it as an efficient way of getting from one place to another. Before the trial, some had an assumption that is not physically demanding to ride an e-bike but revised this assumption after their embodied experience. Others that usually cycled, such as Marie, expressed that the assumption of not getting exercise was reinforced by situational experience and that she would not replace her conventional bike until she got older and was not able to use a manual bike anymore. 


\subsubsection{Multisensory Experiences and Emotional Responses}

When cycling, one sees, hears, smells, feels, and perhaps even tastes the surroundings differently, and arguably more intimately [50], than with other travel modes, especially when compared to the "cocooned" experience of car driving [51]. This has to do with the way one cycles, including the speed, physical effort, vibration, air friction, height, line of sight, weather, sounds, and the routes one takes or avoids. All such aspects are integral parts of the situational dynamic travel environment [44] and the open-air experience of e-biking. E-biking may alter some of these multisensory sensations compared to ordinary cycling. For example, the reduced physical effort combined with the higher aerodynamic resistance of travelling at higher speeds may alter perceptions of riding noise, wind, and thermal conditions.

In the interviews, the informants expressed that weather conditions created both pleasant and unpleasant experiences, and the participants also expressed various levels of tolerance for bad weather. Some cycled no matter what the weather was like, while others only cycled when it was dry and not too cold. Elise, for example, described herself as a "good weather cyclist." Some of the unpleasant experiences related to weather, such as freezing, also had to do with the available equipment, such as suitable clothes, and prior experience and knowledge. The scheme provided participants with a helmet, pannier, and a lock, but not suitable clothes for biking in different types of weather. Many informants did not consider the relevant gear worth purchasing for a trial period, but instead something that they would buy if they had their own e-bike. Accordingly, material elements brought along, such as clothes, are part of staging the participant's mobility performance and experience of comfort [44].

Being outside surrounded by nature was one of the positive aspects of e-biking reported by most by the informants, especially in good weather. The participant's views from the e-bike also exposed recreational sites and scenic views in the suburban landscape, which are reflected in many of the pictures taken by the informants (see Figure $1 b, c, e, i, j, r, s$ ). E-biking was framed as a great way to start and end the day, often contrasting it with the experience of being on crowded busses and trains or sitting in a car queue. Natural settings can evoke different senses [50], something that was a welcomed break in a busy life with days spent inside office buildings. As expressed by Edvard, "Being outside and getting a diversion, feeling the soil, feeling the weather and wind and feeling, are there birds today? Is it raining or not? Experiencing the surroundings; is it sunny? Is it windy? Are there any smells? Using the senses, which one does not do when standing cheek by jowl inside a bus or driving a car. It is a kind of miniature nature experience, which is not wilderness. Thus, one gets to use the senses, feels the wind and nature, and somehow .yes. And it makes it easier to disconnect from what is happening at home, so that when you arrive at work, you are somehow a bit reset, also the same when going home again, to reset the job."

Traveling on an e-bike, being outside, and using different senses thus seems to cover some emotional needs by reducing the stress and the discomfort of hectic commutes and everyday life [52]. One of the most typical emotional responses of e-biking expressed by the participants was having fun. Karoline, who took picture $m$, reflected on how nice it was to be outside in nature and whiz past the cars instead of sitting in a queue of cars feeling angry, which exemplifies the emotional aspect of mobility practices [21,52]. However, being outside in an active travel mode often involves being directly and multisensorially exposed to traffic, pollution, and different weather conditions. Two pictures (Figure 1s,t) were taken at the same place but from two different angles and illustrate an interesting contrast between enjoying natural surroundings (fjords and trees) and experiencing exhaust fumes and pollution from cars passing by at the same time. Studying the embodied and multisensory experiences of e-biking contributes to alternative understandings of material surroundings and illuminates the creation of new mobility cultures and meanings [21,53-55]. Moreover, a perspective that includes the "view from the saddle" highlights how space is actively produced by movement $[14,56]$. 


\subsubsection{Acquiring New Skillsets}

Embodiment capture not only one's physical capabilities and sensory experiences but also the cognitive processes, skillsets, and knowledge that are required to perform an active mobility practice [57]. When the e-bikes were delivered to the informants, most of them received a quick introduction to how the e-bike worked. Accordingly, the intervention facilitated knowledge exchanges between the scheme's workers and the participants. However, this introduction was swift and some seemed a bit overwhelmed by all the information. However, in the interviews, the informants said it was easy to determine the bike's functionality by testing and becoming familiar with the e-bike, even though some perceived it to be intimidating in the beginning. Participating in the trial also allowed the participants to delegate tasks, such as maintenance and repair work, to those working for the scheme, which indicates that one does not need to acquire a maintenance skillset. When the e-bikes were delivered to the participants, the employees in the scheme encouraged them to try to fix it themselves, and if they could not, they were told to call for assistance. Knowing about this opportunity felt reassuring for many participants, as they were trying an e-bike for the first time, and technical issues do occur (see Figure 1u). Amalie, who took the photo, considered calling the scheme operator but asked a colleague who also participated in the scheme instead. Accordingly, she received help to solve the problem. Kristine, a first-time e-biker, told a story about how she had phoned employees of the scheme to obtain help for a technical issue with the e-bike and was very satisfied with the opportunity to obtain help in this way.

Moreover, by participating in the trial, participants were able to acquire new knowledge and skillsets by testing out the e-bike. Through embodied experience, the participants became more familiar and comfortable with the speed of the e-bike and learned how to adjust the speed when cycling. Informants also highlighted the need to include new elements into their daily planning, such as charging the battery, packing differently, finding the right clothes for the weather, and engaging in time-management. Picture $\mathrm{f}$ (Figure 1) exemplifies all the objects one might need to bring when commuting by e-bike; because of the many things one needs to remember, it takes some experience to become used to this process and make it part of a daily routine. Karoline, who usually used public transport to travel to work, said that she was not used to checking the weather forecast before she left home, something she also forgot to do in the trial period, which resulted in a couple of cold, wet, and unpleasant experiences because of unsuitable clothing.

Participating in the scheme also involved learning and determining which routes to take. Acquiring new knowledge about possible routes by testing them was reinforced with the e-bike because the reduced physical effort required made the participants care less if it turned out to be a detour or if the route was challenging, such as routes including many hills. Accordingly, the e-bike was perceived as a flexible way of moving through the different topographical landscapes, route planning was not as present or essential, and exploring new places was easy.

\subsection{Social Interaction}

Social interaction is a core element of mobility because it is one of the enablers and preconditions for mobilities. Social interactions are evident in mobile situations on-site as one encounters others while moving. As Goffman [58] accurately observes, "Take, for example, techniques that pedestrians employ in order to avoid bumping into one another. These seem of little significance. However, there are appreciable numbers of such devices; they are constantly in use and they cast a pattern on street behavior. Street traffic would be a shambles without them" (p. 6). Accordingly, being mobile with others necessitates forms of negotiating in motion [21]. The concept of "mobile with" also covers being mobile with someone intentionally, such as family and friends. Today it is also possible to be mobile with someone in other places through "mediated contact 'stretched' across time and space facilitated by networked technologies" [21] (p. 81). This phenomenon also makes us linked in motion, which, in turn, can change one's embodied experience and how one engages with places and material 
surroundings. Daily mobility practices are also negotiated and coordinated with family, friends, or colleagues back home or at the office.

\subsubsection{Negotiating a Shared Streetscape}

Materiality is essential for staging social interactions and negotiations in motion, and some material settings invite more interactions than others. The concepts of "spaces of prescription" and "spaces of negotiation" [59] capture how material settings intertwine with negotiating in motion. Spaces of prescription are spaces that "encourage" certain types of performance. Some traffic spaces are highly prescribed, such as crossings with traffic lights or streets where all modes of travel have their own separate lanes and speed limits. Accordingly, one needs both tacit and explicit knowledge to be able to conform to the relevant codes, norms, and regulations [60]. Meanwhile, there is always room for negotiations. However, prescribed spaces are more closed for interpretation than "spaces of negotiation", which are more unstable and fluid. Most of the informants expressed a wish for more prescribed spaces designated for cyclists, as spaces of negotiation can create unsafe situations. Spaces of negotiation are evident in the two photos (Figure 1k,i) taken by Martin. The first photo depicts how Martin had to negotiate in motion with pedestrians because there was no designated space for either of the groups, something that he said triggered the emotional response of "road rage." Picture i (Figure 1) displays tram tracks in the road, a type of material infrastructure that an e-biker needs to be aware of; moreover, it shows the potential negotiation with the tram, which can provide a dangerous encounter for the cyclist.

Spaces of negotiation in traffic also include shared streets where car users are deliberately mixed with active modes of transport to slow down speeds and create more leveled playing fields. However, these shared spaces can be experienced as unsafe or unpleasant by cyclists, something that is portrayed in three pictures (Figure 1d,o,p). In all these pictures, the material surroundings "invite" unwanted spatial negotiations between the cars and e-bikes [59]. The cars dominate the road, which demonstrates the materialization of the auto-mobility system [61]. This microgeography of e-biking, knowledge that is facilitated by using GIS and GPS, illuminates how cycling is experienced at a human-scale [62].

\subsubsection{Negotiating Mobility Practices Domestically and Professionally}

Mobility practices are also negotiated and coordinated with people back home. Rau and Sattlegger [63] argue for the importance of including the whole household as the research unit when studying mobility practices, as household members negotiate, coordinate, and re-order practices and activities in relation to each other. Julia, an informant living with her husband and two teenage children, noted that she could not bike to work when her children were younger because she needed to pick them up from kindergarten, to chauffeur them to different activities, and do grocery shopping. The spatiotemporal coordination of the daily activities constrained her perceived mobility options [16]. For these needs, a car was seen as the only viable option. As Julia's children became older, and one of them acquired a driver's license, she was able to cycle, also allowing her son to use the car.

Moreover, Julia emphasized that during the trial period, she realized that the e-bike made daily life easier compared to biking on a conventional bike, as she was not as exhausted when she got home. Kine, an informant with two young children, explained that the e-bike made it possible for her to cycle to work and still manage to travel back home in time to chauffeur her children to their activities. She drove her children to activities because of their locations and times, and since the children did not have e-bikes, it was not seen as an option to cycle with them. The e-bike made it possible for Kine to cycle to work, but it did not replace her need for a car to coordinate household activities. These stories reflect a more general trend: "There are indications that motherhood is becoming increasingly constructed by hypermobilities" [64] (p. 48). This everyday coordination, especially with young children, makes it challenging for many parents to choose an alternative to a car. At the same time, the e-bike can be perceived as an alternative as it can make one "save some time" compared to other ways of travelling, which is essential for many people in their hectic daily lives. 
There are also specific challenges with e-biking, such as balancing the e-bike when travelling with children and all their objects from the kindergarten to the home, even for short distances. Elise expressed the challenge of picking up her children from kindergarten on an e-bike in the following way: "I have a six-year-old, and that's no problem; he can manage, but the two-year-old he wants to hold mummy's hand, and that bike weighs about 25 kilos, you know. Thus, you have to balance the bike and hold the children's hands, which was not easy, it was very stressful. Thus, we would have needed to come up with another solution." Katrine, an informant who usually commuted with a conventional bike, solved this problem by parking her bike at the kindergarten and then walking with the children back and forth from their home. However, she did not do this during the trial period as she did not see it as a secure enough place to park an expensive e-bike.

Mobility practices are negotiated in the household and with colleagues, friends, neighbors, or other family members. This social interaction can also be part of staging mobility practices. Mia, a participant who had fixed working hours, expressed that when she worked very late or very early, the e-bike was not a viable option for her because she would have had to leave her home extremely early or come home very late. Instead, she took her car, which was much faster. However, she said that the e-bike made it more likely to bike even after long shifts, as it was not as exhausting as a conventional bike. For some informants, their activities during working hours also affected whether they used an e-bike for commuting. Helene, a participant with a very demanding job, said that she commuted by public transport on the days she was going to meetings at different locations together with other colleagues. Katrine, on the other hand, thought it was great to use the e-bike to go to job meetings at various locations. For many of the participants, the activities one planned to do directly after work, such as meeting friends, affected whether one chose to ride an e-bike to work. Sara, for example, expressed that "The only time I use the car is if I'm doing something straight after work if I'm meeting someone or picking someone up or maybe if I have to go shopping." These different examples show that there are many types of spatiotemporal coordination and negotiation that are part of staging mobility practices.

\subsubsection{Shaping Mobile Identities}

Studying the embodiment of participants trying out a new mobile practice can also illuminate the shaping of mobile identities and self-presentation [65]. Mobile-self presentation is part of how one stages situational mobility from below [21]. At the individual level, the embodied performance of biking can give the perception of being healthy. It can also create a perception of contributing to larger societal benefits, such as less air pollution. Furthermore, mobile self-presentations are also shaped through mobile social interactions as mobile self-perception can be shaped by comparing one's way of moving with others [21,65]. "Bye, losers," is how Katrine expressed the joy of passing cars on the e-bike. This expression of emotions goes beyond the emotional responses described earlier in this paper, as this relational emotion closely relates to the shaping of mobile identity. Other informants also expressed the satisfaction of passing cars standing in a queue, something that is depicted in picture $\mathrm{n}$ and $\mathrm{m}$ (Figure 1). Kine expresses a similar feeling in the following way: "It is so nice to ride past the queue! Very nice! I think it is one of the best reasons to obtain an electric bike. Yes, across the plain here, where I am used to standing in a queue with my car". Zipping by cars could also apply to ordinary cycling, but this feeling is enhanced on an e-bike, where it happens more effortlessly and at a higher speed. Participating in this scheme and trying an e-bike afforded Katrine and Kine the opportunity to perceive traffic from a different perspective and shape a new mobile identity in meeting with other road users.

Designated spaces for bikers can also have elements of negotiation and social interaction in motion with other cyclists $[21,59]$. Several informants highlighted interactions with one specific group of cyclists, those commonly referred to as MAMILs (Middle-aged Men in Lycra). One finds these cyclists on a particular coastal stretch between Bærum and Oslo typically referred to as the "Tour de finance." It is here that MAMILs compete on the social network and exercise app Strava while commuting from 
(wealthy) suburban neighborhoods to the central business district. The informants applied the label "Tour de Finance" to this particular stretch, as well as to other routes where many MAMILs are present. Informants told stories about passing "racer-cyclists" up hills and expressing affective responses such as joy and empowerment but also expressed sympathy for others struggling up inclines. Selma, one of the informants trying an e-bike for the first time, expressed it in this way: "I found e-biking really fun, especially up hills, when you whiz past those people in Tour de France gear breathing heavily. Hah. I thought that was great!". Changing mobile self-presentation (as cultural changes) can also be a slow process. This is evident through stories told by car-driving informants, such as Kine, who said that she always biked on the sidewalk because she did not want to be "one of the annoying cyclists biking slowly in front of cars". In other words, she still had the mindset or identity of a driver and staged her mobility accordingly.

These examples illustrate that different methods of traveling have different meanings associated with them and that people can perceive travel modes or those using them in specific ways-either wanting to be part of or distancing themselves from such modes [21,65]. In the two examples on passing cars and MAMILs, the e-bike was shown to change the relative strength between the groups, and the joy of overcoming physical barriers was reinforced by passing polluting cars and this specific group of cyclists. This also illustrates how mobile situations and the opportunity to borrow an e-bike for a trial period can change mobile self-understanding and how one sees oneself as a mobile person alongside others and through embodied experiences. Moreover, it shows how people stage themselves through shaping their mobile-self presentation and mobile identity by othering or defining themselves as an outsider or insider in specific mobility-cultures.

\section{Discussion and Conclusions}

Electric bicycles could fulfill an essential role in a transition towards car-independent, sustainable, healthy, and socially inclusive (sub)urban mobility systems. Although e-bike usage has grown considerably in recent years, policy incentives and local initiatives and interventions remain essential to stimulate the further upscaling and mainstreaming of this low-energy transport mode. This paper presents a qualitative study on how a local mobility intervention introducing e-bikes to suburban commuters in Bærum, Norway can trigger changes in daily mobility practices. The objectives were to understand (i) how this low-energy mobility intervention was conceived by its initiators and performed and experienced by its participants, and (ii) how newly formed e-bike practices interweave with existing daily activities and mobility systems.

The findings of this paper complement existing research on sustainable mobility interventions generally and on e-bikes in particular in four crucial ways. First, by contrasting how the e-bike trial was conceived by its initiators and performed and experienced by its participants, we were able to explore where the initiative delivers on its targets and where it fails, as well as the broader effects beyond these targets. The e-bike trial discussed in this study aims to enhance familiarity with e-bikes to promote individual e-bike ownership and ultimately targets the (partial) substitution of car use and ownership. This study finds that the participants were motivated to test (different models of) e-bikes and that doing so allowed them to acquire new knowledge and skillsets that enhanced their familiarity with e-biking while benefiting from the structure, service, and security that the scheme offers. Moreover, participating in the scheme enabled participants to reflect on and revisit their assumptions regarding mobility, sustainability, health, comfort, and wellbeing, and to shape new (less car-dependent) mobile self-presentations, thus allowing them to stage mobility practices from below in new ways [21].

Second, by centering our focus on the situational and relational everyday uses of e-bikes, we revealed that the scheme's capacity to change mobility outcomes can only be understood from the ways newly formed e-bike practices interlock with other everyday activities. Stringent everyday time-space constraints, the complexities of professional and domestic duties coordinated in the household, and the limited capacity to carry along persons or goods make it hard to integrate e-bike into all types of travel. For example, participants that substitute commuting by car with e-biking are often dependent on 
their car for other trips like chauffeuring children or running errands. Sometimes this means activities previously chained into car commutes are now segmented into separate trips, thus restructuring their usual spatiotemporal rhythms.

Third, this focus on the everyday also complements hegemonic econometric conceptualizations of travel as a derived demand with a perspective on mobility that captures its situatedness, relationality, and multisensory embodied performativity. Using photo- and map-elicitation in interviews helped to foreground these crucial dimensions of mobility. It also enabled the production of microgeographical knowledge through the participants' pictures of and reflections on the material surroundings and objects involved in the practice of e-biking, such as urban areas where it is perceived as chaotic to use an e-bike. This knowledge is valuable as it affects related experiences and can enable or prevent participants from using e-bikes in the trial period and from adopting the practice in the future. These methods thus contribute to detailed knowledge on how and where to improve both the intervention and the mobility system.

Fourth, by providing a suburban perspective to an urban-centered field of research, we offer valuable insights into the suburban potential for and contextuality (e.g., built environments) of e-biking. The "view from the saddle" highlights the importance of nature and recreational sites and indicates there is a high potential for promoting active travel modes in the suburbs. Accordingly, sustainable transport interventions introducing active transport modes, such as e-bikes, can have a significant impact on reducing emissions from suburban commutes and mobility, which are insights that contribute to the reframing of car-dependent perceptions of suburban environments and mobility. Exploring the participant's appropriation of this new technology has illuminated how the e-bike is well suited for medium-range distances, which are characteristic for much suburban travel.

The findings of this study have several implications for the design of interventions, as well as for policy and planning. First, the participants in this study were positive towards the supporting structures of the scheme (e.g., the maintenance and repair of the e-bike), which indicates that there might be a potential for alternatives to purchase-oriented schemes, thereby permanently enhancing the supporting structures of sustainable mobility practices. Schemes that are not based on individual ownership will also reduce the barrier for buying an expensive e-bike and can reduce some of the inequitable outcomes in the form of access to e-bikes [8]. We found that the price of purchasing an e-bike is a prominent barrier for adopting this mobility practice after the intervention. Second, when pursuing the promotion of e-bike ownership, it is worth considering implementing a national subsidizing scheme to mitigate the high purchase prices of e-bikes, similar to what is done for electric vehicles in Norway. EVs are subsidized through different economic incentives at the national level, which have contributed to a massive demand for EVs, while national fiscal schemes support neither electric nor conventional bikes. It would also be possible to integrate discounted e-bike purchase options into local schemes, but these should be long-term solutions to secure predictability and stability. Third, parking is an important factor in the choice to travel by e-bike. Some of our informants indicated inadequate access to car parks at work as a factor that makes the e-bike, which can often be parked more flexibly at work locations, a more attractive option for commuting. More restrictions on car parking at suburban workplaces can further enhance the competitiveness of commuting by e-bike. However, this study also revealed the challenges related to the parking of e-bikes themselves: (i) the design of the bicycle racks and locks, and (ii) the access to safe and secure parking opportunities at various locations, including work, home, and service functions. Fourth, our findings reveal the need to improve overall cycling infrastructures. It was evident in the findings that the participants wanted more prescribed and designated spaces for bikes, particularly in more densely built areas, as revealed by map-elicitation.

Based on the barriers and opportunities identified by the participants, we have identified several factors that can contribute to making a mobility intervention more successful in triggering a change. We synthesized these and other success factors, both scheme-related and contextual factors, in Table 1. 
Table 1. Success factors for an e-bike intervention.

\begin{tabular}{ll}
\hline Factors Related to the Intervention Itself & Supportive Contextual Factors \\
\hline $\begin{array}{l}\text { 1. Simplicity (e.g., in terms of e-bike delivery and collection) } \\
\text { 2. Dedicated support systems (e.g., maintenance and repair) }\end{array}$ & $\begin{array}{l}\text { 1. Good cycling infrastructure (e.g., integrated/unobstructed cycling } \\
\text { network, wider and segregated lanes) }\end{array}$ \\
\hline $\begin{array}{l}\text { 3. High quality e-bikes and equipment (e.g., pannier, lock) } \\
\text { 4. Lending of supportive equipment } \\
\text { (e.g., weather-proof clothing) }\end{array}$ & $\begin{array}{l}\text { 2. Attractive cycling environments (e.g., green areas, not adjacent to } \\
\text { highways, reduced noise/air-pollution) }\end{array}$ \\
\hline $\begin{array}{l}\text { 5. Clear instructions for using the e-bike and the equipment } \\
\text { 6. Not only purchase-oriented but also sharing-based schemes }\end{array}$ & $\begin{array}{l}\text { 3. Secure bicycle parking at key locations } \\
\text { (e.g., work/shopping centers) }\end{array}$ \\
\hline $\begin{array}{l}\text { 7. Integrate discounted e-bike purchase options into a scheme } \\
\text { 8. Longer and user-adaptable e-bike lending periods to enhance } \\
\text { testing, learning, and familiarity }\end{array}$ & $\begin{array}{l}\text { 4. Supportive facilities at key locations, (e.g., wardrobes, changing } \\
\text { rooms, charging opportunities, storage) }\end{array}$ \\
\hline $\begin{array}{l}\text { 9. Facilitate knowledge sharing between users and feedback } \\
\text { loops between users and operators }\end{array}$ & \\
\hline
\end{tabular}

To enable a sustainable transport transition there is also a need to focus on how existing mobility systems cater to different travel modes and lives and how suitable e-bikes are perceived to be for different activities in the current system (see Table 2).

Table 2. The suitability of e-biking for different activities.

\begin{tabular}{ll}
\hline Activities the E-Bike is Particularly Suited for & Activities Where the E-Bike May be Less Attractive \\
\hline 1. Travelling alone or with other e-bike users & 1. Travelling with regular cyclists \\
2. Leisure trips into nature & 2. Trips where street parking in urban areas is required \\
3. Commuting & 3. Chauffeuring children \\
4. Visiting friends and family & 4. Travelling with family and friends \\
5. Carrying smaller goods and running daily errands & 5. Carrying larger goods and running weekly errands \\
6. Middle-range distances & 6. Short (urban) trips and regional/long-distance travel \\
7. Non-chained trips & 7. Chained trips \\
8. Physical exercise & 8. Intense physical exercise \\
\hline
\end{tabular}

To promote e-bike use and make it more attractive for groups heavily relying on these challenging activities in their daily lives, we argue that there is a need to improve current mobility systems (e.g., cycle infrastructures) to make it easier to undertake chained trips, and to promote different bike types (e.g., cargo bikes), making it easier to carry goods and people. Moreover, there is a need to improve parking opportunities at locations like schools, kindergartens, and shopping centers, potentially with overnight parking and with charging and storage facilities. This might make it easier to substitute car use with active transport modes and also due to the complex trip chaining patterns that are typical in our hectic everyday lives, especially for parents with small children.

This explorative study has demonstrated that there is great potential in combining visual elicitation methods (maps and photos) with mobile methods (GPS-tracking) in the production of microgeographical and mobile knowledge. GPS-tracking and map-elicitation also make it possible to pinpoint places where e-biking works well and has great potential to succeed, as well as places that are perceived as cumbersome or unsafe and in need of improvement. This knowledge will be passed on to the scheme's initiators. However, there is a need for a more detailed discussion on the potential and limitations of using participatory visual mobile methods in transport geography, and the capacity of using such methods to disseminate qualitative research to policy-makers.

Structuring daily life with an e-bike in the existing mobility system seems to be the informant's most significant barrier for adopting this new mobility practice. Accordingly, there is a need for sustainable transport interventions to shift the focus to the bundles of practices that might comprise a more sustainable society [19], as well as accommodating a mobility system where a car is not perceived as the only solution. This indicates that research on sustainable transport interventions would benefit from integrating daily life and situational experiences into the analysis. Moreover, follow up studies need to be conducted to determine whether this scheme will result in the eventual purchases of e-bikes and the actual substitutions of car use and ownership. Ideally, such studies should GPS track not only e-bike usage but also other transport modes, before, during, and after the scheme's trial period. 
This could further deepen the discussions on the spatiotemporal interlocking of newly formed e-bike practices with everyday mobilities.

Author Contributions: Conceptualization, R.D.W. and L.B.; methodology, R.D.W.; software, R.D.W.; validation, n/a; formal analysis, n/a.; investigation, R.D.W.; resources, R.D.W,; data curation, R.D.W.; writing-original draft preparation, R.D.W.; writing-review and editing, L.B. and R.D.W.; visualization, L.B. and R.D.W.; supervision, L.B.; project administration, R.D.W. and L.B.; funding acquisition, L.B. All authors have read and agreed to the published version of the manuscript.

Funding: This research was funded by the Research Council of Norway, EnergiX Programme, grant number 255189 and the APC will be funded by the Department of Sociology and Human Geography, University of Oslo.

Acknowledgments: SmartCity Bærum.

Conflicts of Interest: The authors declare no conflict of interest. The funders had no role in the design of this study; in the collection, analyses, or interpretation of data; in the writing of the manuscript, or in the decision to publish the results.

\section{References}

1. Phelps, N.A.; Wood, A.M.; Valler, D.C. A Postsuburban World? An Outline of a Research Agenda. Environ. Plan. A 2010, 42, 366-383. [CrossRef]

2. Engebretsen, Ø.; Næss, P.; Strand, A. Residential location, workplace location and car driving in four Norwegian cities. Eur. Plan. Stud. 2018, 26, 2036-2057. [CrossRef]

3. Fishman, E.; Cherry, C. E-bikes in the Mainstream: Reviewing a Decade of Research. Transp. Rev. 2015, 36, 72-91. [CrossRef]

4. Jones, T.; Harms, L.; Heinen, E. Motives, perceptions and experiences of electric bicycle owners and implications for health, wellbeing and mobility. J. Transp. Geogr. 2016, 53, 41-49. [CrossRef]

5. Popovich, N.; Gordon, E.; Shao, Z.; Xing, Y.; Wang, Y.; Handy, S. Experiences of electric bicycle users in the sacramento, california area. Travel Behav. Soc. 2014, 1, 37-44. [CrossRef]

6. Cairns, S.; Behrendt, F.; Raffo, D.; Beaumont, C.; Kiefer, C. Electrically-assisted bikes: Potential impacts on travel behaviour. Transp. Res. Part A 2017, 103, 327-342. [CrossRef]

7. Dill, J.; Rose, G. Electric Bikes and Transportation Policy Insights from Early Adopters. Transp. Res. Record 2012, 2314, 1-6. [CrossRef]

8. Behrendt, F. Why cycling matters for electric mobility: Towards diverse, active and sustainable e-mobilities. Mobilities 2018, 13, 64-80. [CrossRef]

9. Ydersbond, I.M.; Veisten, K. The Climate Effect of E-Bikes: Documentation of Which Factors Drive and Hinder Use of E-Bikesin Norway and E-Bikes' Contribution to Reduction of Greenhouse Gas Emissions in Norwegian Municipalities; Institute of Transport Economics: Oslo, Norway, 2019.

10. Schwanen, T. The Bumpy Road toward Low-Energy Urban Mobility: Case Studies from Two UK Cities. Sustainability 2015, 7, 7086-7111. [CrossRef]

11. Geels, F.W. Technological transitions as evolutionary reconfiguration processes: A multi-level perspective and a case-study. Res. Policy 2002, 31, 1257-1274. [CrossRef]

12. Geels, F.W. The multi-level perspective on sustainability transitions: Responses to seven criticisms. Environ. Innov. Soc. Transit. 2011, 1, 24-40. [CrossRef]

13. Hoogma, R. Experimenting for Sustainable Transport: The Approach of Strategic Niche Management; Spon Press: London, UK, 2002.

14. Lefebvre, H. The Production of Space; Blackwell: Oxford, UK, 1991.

15. Pantzar, M.; Shove, E. Understanding innovation in practice: A discussion of the production and re-production of Nordic Walking. Technol. Anal. Strateg. Manag. 2010, 22, 447-461. [CrossRef]

16. Kwan, M.-P. Beyond Space (As We Knew It): Toward Temporally Integrated Geographies of Segregation, Health, and Accessibility: Space-Time Integration in Geography and GIScience. Ann. Assoc. Am. Geogr. 2013, 103, 1078-1086. [CrossRef]

17. Freudendal-Pedersen, M. Mobility in Daily Life: Between Freedom and Unfreedom; Ashgate: Farnham, UK, 2009.

18. Urry, J. Mobilities; Polity: Cambridge, UK, 2007.

19. Spurling, N.; McMeekin, A. Interventions in practices: Sustainable mobility policies in England In Social Practices, Interventions and Sustainability; Strengers, Y., Maller, C., Eds.; Routledge: Oxfordshire, UK, 2015; pp. 78-94. 
20. Sheller, M.; Urry, J. The New Mobilities Paradigm. Environ. Plan. A 2006, 38, 207-226. [CrossRef]

21. Jensen, O.B. Staging Mobilities; Routledge: London, UK, 2013.

22. Fylkeskommune, A.; Kommune, O. Regional plan for areal og transport i Oslo og Akershus. Hentet Mars 2015, 11, 2016.

23. St.meld.nr.33. National Transport Plan 2018-2029: A Targeted and Historic Commitment to the Norwegian Transport Sector; Norwegian Ministry of Transport and Communications: Oslo, Norway, 2016-2017.

24. Elbil. Available online: https://elbil.no/over-200-000-elbiler-i-norge/ (accessed on 5 February 2020).

25. Hjorthol, R.; Engebretsen, Ø.; Uteng, T.P. 2013/14 Norwegian Travel Survey—Key Results; The Institute of Transport Economics Oslo; Institute of Transport Economics: Oslo, Norway, 2014.

26. Büscher, M.; Urry, J. Mobile Methods and the Empirical. Eur. J. Soc. Theory 2009, 12, 99-116. [CrossRef]

27. Evans, J.; Jones, P. The walking interview: Methodology, mobility and place. Appl. Geogr. 2011, 31, 849-858. [CrossRef]

28. Moore-Cherry, N.; Crossa, V.; O'donnell, G. Investigating urban transformations: GIS, map-elicitation and the role of the state in regeneration. Urban Stud. 2015, 52, 2134-2150. [CrossRef]

29. Larsen, J. Practices and Flows of Digital Photography: An Ethnographic Framework. Mobilities 2008, 3, 141-160. [CrossRef]

30. Latham, A. Research, Performance, and Doing Human Geography: Some Reflections on the Diary-Photograph, Diary-Interview Method. Environ. Plan. A 2003, 35, 1993-2017. [CrossRef]

31. Rose, G. Visual Methodologies: An Introduction to Researching with Visual Materials, 4th ed.; Sage: London, UK, 2016.

32. Murray, L. Looking At and Looking Back: Visualization in Mobile Research. Qual. Res. 2009, 9, 469-488. [CrossRef]

33. Strengers, Y.; Maller, C. (Eds.) Introduction: Social practices, intervention and sustainability: Beyond behaviour change. In Social practices, intervention and sustainability: Beyond behaviour change; Routledge: Oxfordshire, UK, 2015; pp. 1-12.

34. Schwanen, T.; Banister, D.; Anable, J. Scientific research about climate change mitigation in transport: A critical review. Transp. Res. Part A 2011, 45, 993-1006. [CrossRef]

35. Shove, E. Beyond the ABC: Climate change policy and theories of social change.(attitude, behaviour, and choice). Environ. Plan. A 2010, 42, 1273-1285. [CrossRef]

36. Hägerstrand, T. What about people in Regional Science? Pap. Reg. Sci. Assoc. 1970, 24, 6-21. [CrossRef]

37. Baerum Kommune. Available online: https://www.baerum.kommune.no/politikk-og-samfunn/barum-2035/ klimaklok-kommune/artikler-og-saker/smartbike-barum---elsykkel-pool/ (accessed on 4 February 2020).

38. Dieleman, F.M.; Dijst, M.; Burghouwt, G. Urban Form and Travel Behaviour: Micro-level Household Attributes and Residential Context. Urban Stud. 2002, 39, 507-527. [CrossRef]

39. Zegras, C. The Built Environment and Motor Vehicle Ownership and Use: Evidence from Santiago de Chile. Urban Stud. 2010, 47, 1793-1817. [CrossRef]

40. Cervero, R.; Kockelman, K. Travel demand and the 3Ds: Density, diversity, and design. Transp. Res. Part D 1997, 2, 199-219. [CrossRef]

41. Holden, E.; Norland, I.T. Three Challenges for the Compact City as a Sustainable Urban Form: Household Consumption of Energy and Transport in Eight Residential Areas in the Greater Oslo Region. Urban Stud. 2005, 42, 2145-2166. [CrossRef]

42. Næss, P. Urban Structure Matters: Residential Location, Car Dependence and Travel Behaviour; Routledge: London, UK, 2006; Volume 13.

43. Næss, P.; Røe, P.G.; Larsen, S.L. Travelling Distances, Modal Split and Transportation Energy in Thirty Residential Areas in Oslo; Norsk Institutt for by- og Regionforskning: Oslo, Norway, 1996; Volume 3.

44. Dijst, M. Space-Time Integration in a Dynamic Urbanizing World: Current Status and Future Prospects in Geography and GIScience: Space-Time Integration in Geography and GIScience. Ann. Assoc. Am. Geogr. 2013, 103, 1058-1061. [CrossRef]

45. Hannam, K.; Sheller, M.; Urry, J. Editorial: Mobilities, Immobilities and Moorings. Mobilities 2006, 1, 122. [CrossRef]

46. Merriman, P. Mobility Infrastructures: Modern Visions, Affective Environments and the Problem of Car Parking. Mobilities 2016, 11, 83-98. [CrossRef] 
47. Aldred, R.; Jungnickel, K. Matter in or out of place? Bicycle parking strategies and their effects on people, practices and places. Soc. Cult. Geogr. 2013, 14, 604-624. [CrossRef]

48. Larsen, J. Bicycle Parking and Locking: Ethnography of Designs and Practices. Mobilities 2017, 12, 53-75. [CrossRef]

49. Latour, B. Mixing humans and nonhumans together: The sociology of a door-closer. Soc. Probl. 1988, 35, 298-310.

50. Böcker, L.; Dijst, M.; Faber, J.; Helbich, M. En-route weather and place valuations for different transport mode users. J. Transp. Geogr. 2015, 47, 128-138. [CrossRef]

51. Bijsterveld, K. Acoustic Cocooning: How the Car became a Place to Unwind. Senses Soc. 2010, 5, $189-211$. [CrossRef]

52. McQuoid, J.; Dijst, M. Bringing emotions to time geography: The case of mobilities of poverty. J. Transp. Geogr. 2012, 23, 26-34. [CrossRef]

53. Aldred, R.; Jungnickel, K. Why culture matters for transport policy: The case of cycling in the UK. J. Transp. Geogr. 2014, 34, 78-87. [CrossRef]

54. Spinney, J. A Place of Sense: A Kinaesthetic Ethnography of Cyclists on Mont Ventoux. Environ. Plan. D Soc. Space 2006, 24, 709-732. [CrossRef]

55. Spinney, J. Cycling the City: Non-Place and the Sensory Construction of Meaning in a Mobile Practice. In Cycling and Society; Horton, D., Rosen, P., Cox, P., Eds.; Ashgate: Aldershot, UK, 2007; pp. 47-66.

56. Massey, D. For Space; Sage: London, UK, 2005.

57. Shove, E.; Pantzar, M.; Watson, M. The Dynamics of Social Practice: Everyday Life and How It Changes; Sage: Los Angeles, CA, USA, 2012.

58. Goffman, E. Relations in Public: Microstudies of the Public Order; Allen Lane The Penguin Press: London, UK, 1971.

59. Murdoch, J. The spaces of actor-network theory. Geoforum 1998, 29, 357-374. [CrossRef]

60. Cox, P. Cycling: A Sociology of Velo-Mobility; Routledge: London, UK; New York, NY, USA, 2019.

61. Dennis, K.; Urry, J. After the Car; Polity Press: Cambridge, UK, 2009.

62. Gehl, J. Livet Mellem Husene; Arkitektens Forlag: København, Denmark, 1971.

63. Rau, H.; Sattlegger, L. Shared journeys, linked lives: A relational-biographical approach to mobility practices. Mobilities 2018, 13, 45-63. [CrossRef]

64. Murray, L. Motherhood, Risk and Everyday Mobilities. In Gendered Mobilities; Uteng, T.P., Cresswell, T., Eds.; Ashgate: Aldershot, UK, 2008; pp. 47-59.

65. Aldred, R. 'On the outside': Constructing cycling citizenship. Soc. Cult. Geogr. 2010, 11, 35-52. [CrossRef] 